\title{
Incidence and risk factors for term low birth weight babies in a tertiary care hospital in Kerala
}

\author{
Sheela Jacob, Ancy T. Jacob* \\ Department of Obstetrics and Gynecology, Obstetrics and Gynaecology, Travancore Medical College Kollam, \\ Kerala, India
}

Received: 17 March 2021

Accepted: 03 April 2021

*Correspondence:

Dr. Ancy T. Jacob,

E-mail: drancytjacob@gmail.com

Copyright: $\odot$ the author(s), publisher and licensee Medip Academy. This is an open-access article distributed under the terms of the Creative Commons Attribution Non-Commercial License, which permits unrestricted non-commercial use, distribution, and reproduction in any medium, provided the original work is properly cited.

\begin{abstract}
Background: Birth weight of $<2.5 \mathrm{~kg}$ at birth is considered low birth weight and impacts the individual's health during their adult life. Babies are born with low birth weight, both in term and preterm deliveries. This study aims to find the incidence of term low birth weight babies (TLBW) and the maternal risk factors associated with the same.

Methods: This case-control study was conducted on 166 pregnant women who had term live births during the study period July 2019 to December 2020. Inclusion criteria: Women with a live singleton TLBW $(<2.5 \mathrm{~kg})$ - cases (63) and normal birth weight babies - controls (103). Control group selection was 1:2 proportion as per the cases. Exclusion criteria consisted of women with multiple gestations. Binary and categorical variables were presented using counts and percentages. Independent sample t-test was used to compare two continuous variables, and the chi-square test/Fisher's exact test was used to find the association of categorical variables.

Results: 1344 live births were reported during the study period, of which 63 cases were TLBW babies with an incidence of $4.68 \%$. Among the baseline parameters, significant difference was observed only in body mass index (BMI). After assessing the common risk factors like anemia, urinary tract infection (UTI), genital tract infection, gestational diabetes mellitus (GDM), and gestational hypertension, only hypothyroidism showed significant association with TLBW (OR: 2.240, 95\% CI:0.98-5.13, $\mathrm{p}=0.006$ ).

Conclusions: The incidence of TLBW babies was $4.68 \%$, which is low compared with other studies. Hypothyroidism shows significant association with TLBW in this study which was not observed in previous literature.
\end{abstract}

Keywords: Term low birth weight, Hypothyroidism, Risk factors, Neonatal characteristics

\section{INTRODUCTION}

Birth weight decides the growth and existence of an infant. Low birth weight (LBW) is considered as a major risk factor for both morbidity and mortality of neonates and children under five. ${ }^{1}$ World Health Organization (WHO) defines low birth weight as the weight at birth less than 2500 grams. $^{2} \mathrm{LBW}$ incidence in India is between $25-30 \%$; IUGR contributes $60-65 \%$ of the cases. ${ }^{3} \mathrm{LBW}$ is a serious public health issue in both developed and developing countries as it has a long-term health impact on adult life. They are at higher risk of developing hypertension, diabetes, lung disease, heart disease, etc., in their adult life.
They are also at risk of abnormal cognitive development, neurological impairment, and poor school performance. ${ }^{4}$

The incidence of low birth weight is estimated to be $15 \%$ worldwide and is mainly found in developing countries. ${ }^{5}$ The newborn mortality rate in India is 23/1000 live births, and the infant mortality rate in Kerala is 6/1000 live births. ${ }^{6,7}$

Several medical disorders complicating pregnancy like hypertension, diabetes mellitus, tuberculosis and other antenatal complications like antepartum hemorrhage, anemia, urinary tract infection, etc. affect the birth weight 
of the baby. Other maternal risk factors for LBW babies are smoking during pregnancy, drug intoxication, and alcohol/tobacco ingestion. ${ }^{5}$ Moreover, the women born with LBW have a higher chance of having LBW babies in the future. When they enter their adulthood, they are prone for hypertension and diabetes, which increases their chance of having LBW babies. Hence, LBW babies are a matter of great concern. ${ }^{4}$

Kerala state is notable for its health sector accomplishments. Compared to the national average, it is a unique state in India having a different demographic and health indicators. ${ }^{8}$ Most health indices are equivalent to developed countries, but LBW has been reported to be having a high proportion compared to developed countries. ${ }^{9,10}$ The incidence of LBW can be reduced by identifying the risk factors that contribute to low birth weight.

The study aims to determine the incidence of TLBW and the maternal risk factors contributing to the TLBW in an institution that caters to the urban population in South Kerala.

\section{METHODS}

This case control study was conducted among 166 women who had term live births in a tertiary care center. The study was conducted from July 2019 to December 2020. There were a total of 1344 live births during the study period. All the women who delivered a live singleton TLBW baby $<2.5 \mathrm{~kg}$ during the study period were considered as cases and the women with live singleton term normal birth weight babies were considered as controls. Control group were selected in a 1:2 proportion as per the cases. Women with multiple gestations were excluded from the study.

The data were collected from their medical records and were analyzed. Baseline variables including age, parity, height, and weight at first antenatal visit and body mass index (BMI) were collected. Past obstetric details including prior abortions, still births, preterm births, and previous baby details like birth weight were taken. Antenatal risk factors including antepartum hemorrhage, urinary tract infection, anemia, gestational hypertension, and diabetes in pregnancy, thyroid and other chronic medical disorder details were collected from their case records and entered in a proforma.

\section{Statistical analysis}

Descriptive statistics will be used to present all outcomes; normally distributed data presented by mean and standard deviation (SD). Binary and categorical variables will be presented using counts and percentages. For the comparison of two continuous variables independent sample t test were used and chi-square test/Fishers exact test used to find the association of categorical variables. Data entered in Microsoft excel and analyzed using statistical package for the social sciences (SPSS) version 20.00 .

\section{RESULTS}

There were a total of 1344 live births during the study period. The incidence of TLBW babies was $4.68 \%$. This case-control study was conducted among 166 pregnant women who had term singleton live births. Of them, 63 had live singleton TLBW babies (cases) and 103 had live term normal birth weight babies (controls). Among the cases, the range of age varied from 20-38 years with an average of $27.16 \pm 4.13$ years and the age of control group varied from 20-36 years with an average of $27.20 \pm 3.88$ years and the minor difference observed was not significant $(p=0.669)$. Height distribution showed the height varied from 151-174 cm with an average height of $159.57 \pm 4.32 \mathrm{~cm}$ in the case group and in the control group height ranges from 144-172 cm with mean height of $158.35 \pm 4.25(\mathrm{p}=0.407)$. The observed difference in weight of the mother during antenatal visit, between the two groups was not significant $(p=0.148)$. When the BMI distribution among both groups were compared, the case group had more underweight mothers, control group had more overweight and obese mothers, and mothers with normal BMI were almost equal in both groups and the observations were statistically significant $(\mathrm{p}=0.006)$.

Parity distribution showed that $60.3 \%$ of the mothers in the case group were primi gravida and $39.7 \%$ were multi gravida, and in the control group, $47.6 \%$ were primi and $52.5 \%$ were multi gravida $(\mathrm{p}=0.149)$. Majority of the mothers in both case and control groups had no history of abortions $(\mathrm{p}=0.501)$. History of infertility was observed in $6.3 \%$ of case group and $3.9 \%$ of control group $(p=0.711)$ (Table 1). Risk factors distribution showed the incidence of each risk factor in the study groups. The observed difference seems to be more in thyroid disorders hypothyroidism (Figure 1).

When compared, anemia was found 0.442 times more likely to occur in women with low-birth weight babies than with normal birth weight babies. Urinary tract infection (UTI) were 0.975 times more likely to have in low-birthweight group and genital tract infection were 3.647 times more in the case group than in control group. Gestational hypertension were 0.574 times, gestational diabetes were 1.186 times and antepartum hemorrhage were 0.618 times more in the low-birth-weight group. All these risk factors were not significantly associated among the study groups.

Hypothyroidism was found 2.240 times more in the lowbirth weight (case) group and the association was statistically significant $(\mathrm{p}=0.006)$ (Table 2$)$.

Neonatal characteristics of the study population showed that, in the case group, $60.3 \%$ were males and $39.7 \%$ were females and in the control group $52.4 \%$ were males and $47.6 \%$ were females. We did not have enough evidence to prove the association between two groups $(\mathrm{p}=0.339)$. Birth 
weight of newborn babies among the cases varied from 2.07 to 2.47 with an average of $2.35 \pm 0.107 \mathrm{~kg}$ and among the controls birth weight varied from 2.61 to 4.22 with an average of $3.06 \pm 0.315 \mathrm{~kg}$. This observed difference between means was highly statistically significant $(\mathrm{p}<0.001)$ (Table 3).

Table 1: Baseline characteristics of the study population.

\begin{tabular}{|c|c|c|}
\hline \multirow{2}{*}{ Variable } & Cases (63) & Controls (103) \\
\hline & Frequency and percentage & Frequency and percentage \\
\hline \multicolumn{3}{|l|}{ Age (in years) } \\
\hline Range & $20-38$ & $20-36$ \\
\hline Mean \pm SD & $27.16 \pm 4.13$ & $27.20 \pm 3.88$ \\
\hline $20-25$ & $22(34.9)$ & $41(39.8)$ \\
\hline $25-30$ & $27(42.9)$ & $37(35.9)$ \\
\hline$>30$ & $14(22.2)$ & $25(24.3)$ \\
\hline \multicolumn{3}{|l|}{ Height (in cm) } \\
\hline Range (in $\mathrm{cm}$ ) & $151-174$ & $144-172$ \\
\hline Mean \pm SD & $159.57 \pm 4.32$ & $158.35 \pm 4.25$ \\
\hline $144-154$ & $4(6.3)$ & $12(11.7)$ \\
\hline $154-164$ & $53(84.1)$ & $85(82.5)$ \\
\hline $164-174$ & $6(9.5)$ & $6(5.8)$ \\
\hline \multicolumn{3}{|l|}{ Weight (in kg) } \\
\hline Range (in kg) & $44-93$ & $40-94$ \\
\hline Mean \pm SD & $61.41 \pm 10.04$ & $63.50 \pm 10.67$ \\
\hline $40-50$ & $10(15.9)$ & $11(10.7)$ \\
\hline $50-60$ & $20(31.7)$ & $33(32)$ \\
\hline $60-70$ & $9(44.4)$ & $39(37.4)$ \\
\hline$>70$ & $5(7.9)$ & $20(19.4)$ \\
\hline \multicolumn{3}{|l|}{ Body mass index $\left(\mathrm{kg} / \mathrm{m}^{2}\right)$} \\
\hline Under weight $(<18.5)$ & $5(8.1)$ & $1(1)$ \\
\hline Normal weight (18.5-24.9) & $15(24.2)$ & $30(29.4)$ \\
\hline Overweight (25-29.9) & $36(58.1)$ & $45(44.1)$ \\
\hline Obese $(\geq 30)$ & $6(9.7)$ & $26(25.5)$ \\
\hline \multicolumn{3}{|l|}{ Parity (gravida) } \\
\hline Primi & $38(60.3)$ & $49(47.6)$ \\
\hline Multi & $25(39.7)$ & $54(52.5)$ \\
\hline \multicolumn{3}{|l|}{ Prior abortion } \\
\hline One & $8(12.70)$ & $21(20.40)$ \\
\hline Two & $1(1.60)$ & $2(1.90)$ \\
\hline Four & 0 & $1(1)$ \\
\hline No abortions & $54(85.70)$ & $79(76.70)$ \\
\hline \multicolumn{3}{|l|}{ History of infertility } \\
\hline Yes & $4(6.3)$ & $4(3.9)$ \\
\hline No & $59(93.7)$ & $99(96.1)$ \\
\hline
\end{tabular}

a: Chi square test, b: Fishers exact test, *significant

Table 2: Association of antenatal risk factors between the study groups.

\begin{tabular}{|lllllll|}
\hline Risk factors & $\begin{array}{l}\text { Cases (63) } \\
\text { Frequency (\%) }\end{array}$ & $\begin{array}{l}\text { Control (103) } \\
\text { Frequency (\%) }\end{array}$ & Chi square value & P value & Odds ratio & 95\% CI \\
\hline Anemia & & & & & \\
\hline Yes & $4(6.3)$ & $3(2.9)$ & \multirow{2}{*}{$1.143^{\mathrm{b}}$} & 0.247 & 0.443 & \multirow{2}{*}{$0.096-2.05$} \\
\hline No & $59(93.7)$ & $100(97.1)$ & & & & \\
\hline Urinary tract infection (UTI) & & \multirow{2}{*}{$3.488^{\mathrm{a}}$} & 0.194 & 0.975 & $0.41-0.23$ \\
\hline Yes & $8(15.9)$ & $16(15.5)$ & $87(84.5)$ & & &
\end{tabular}




\begin{tabular}{|c|c|c|c|c|c|c|}
\hline \multirow{2}{*}{ Risk factors } & Cases (63) & Control (103) & \multirow[b]{2}{*}{ Chi square value } & \multirow[b]{2}{*}{ P value } & \multirow[b]{2}{*}{ Odds ratio } & \multirow{2}{*}{$95 \% \mathrm{CI}$} \\
\hline & Frequency $(\%)$ & Frequency $(\%)$ & & & & \\
\hline \multicolumn{7}{|c|}{ Genital tract infection } \\
\hline Yes & $2(2.7)$ & $11(10.7)$ & \multirow{2}{*}{$3.050^{\mathrm{b}}$} & \multirow{2}{*}{0.069} & \multirow{2}{*}{3.647} & \multirow{2}{*}{$0.78-17.03$} \\
\hline No & $61(96.8)$ & $92(89.3)$ & & & & \\
\hline \multicolumn{7}{|c|}{ Gestational hypertension } \\
\hline Yes & $9(14.3)$ & $9(8.7)$ & \multirow{2}{*}{$1.245^{\mathrm{a}}$} & \multirow{2}{*}{0.194} & \multirow{2}{*}{0.574} & \multirow{2}{*}{$0.215-1.54$} \\
\hline No & $54(85.7)$ & $94(91.3)$ & & & & \\
\hline \multicolumn{7}{|l|}{ GDM } \\
\hline Yes & $9(14.3)$ & $17(16.5)$ & \multirow{2}{*}{$0.146^{\mathrm{a}}$} & \multirow{2}{*}{0.441} & \multirow{2}{*}{1.186} & \multirow{2}{*}{$0.49-2.85$} \\
\hline No & $54(85.7)$ & $86(83.5)$ & & & & \\
\hline \multicolumn{7}{|c|}{ Antepartum hemorrhage } \\
\hline Yes & $0(0)$ & $1(1.0)$ & \multirow{2}{*}{$0.615^{\mathrm{b}}$} & \multirow{2}{*}{0.62} & \multirow{2}{*}{0.618} & \multirow{2}{*}{$0.55-0.69$} \\
\hline No & $63(100.0)$ & $102(99.0)$ & & & & \\
\hline \multicolumn{7}{|c|}{ Hypothyroidism } \\
\hline Yes & $9(14.3)$ & $28(27.2)$ & \multirow{2}{*}{$3.755^{\mathrm{a}}$} & \multirow{2}{*}{$0.006^{*}$} & \multirow{2}{*}{2.240} & \multirow{2}{*}{$0.98-5.13$} \\
\hline No & $54(85.7)$ & $75(72.8)$ & & & & \\
\hline
\end{tabular}

a: Chi square test, b: Fishers exact test, *significant

Table 3: Neonatal characteristics of the study population.

\begin{tabular}{|c|c|c|c|}
\hline Characteristics & Cases (63) & Controls (103) & P value \\
\hline \multicolumn{4}{|c|}{ Gender of the baby } \\
\hline Male & $38(60.3 \%)$ & $54(52.4 \%)$ & \multirow{2}{*}{$0.339^{\mathrm{a}}$} \\
\hline Female & $25(39.7 \%)$ & $49(47.6 \%)$ & \\
\hline \multicolumn{4}{|c|}{ Weight of the baby } \\
\hline Range & 2.07 to 2.47 & 2.61 to 4.22 & \multirow{2}{*}{$<0.001 * 1$} \\
\hline Mean \pm SD & $2.35 \pm 0.107$ & $3.06 \pm 0.315$ & \\
\hline
\end{tabular}

a: Chi square test, b: Fishers exact test, *significant

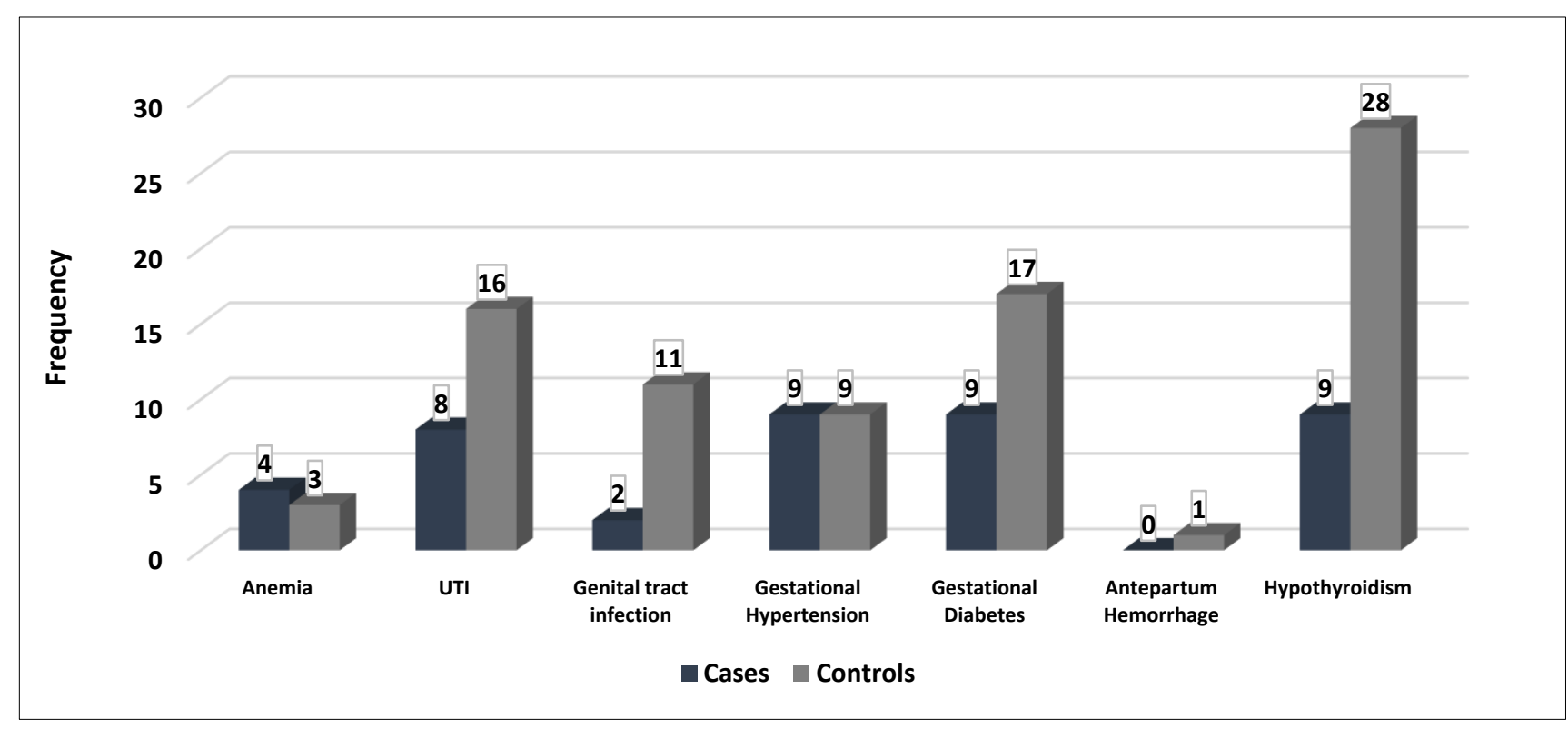

Figure 1: Distribution of risk factors among the study groups.

\section{DISCUSSION}

This case-control study was conducted on 166 pregnant women who had term live births, out of total 1344 live births during the study period, in an urban tertiary care center located in South Kerala. The study aims to find the incidence of TLBW babies and the maternal risk factors contributing to the TLBW. The incidence of TLBW babies 
in this study was $4.68 \%$. The studies conducted in different countries on the incidence of TLBW showed that it is $3.7 \%$ in Brazil, $2 \%$ in China, $12 \%$ in Ethiopia, $10.6 \%$ in Pakistan, and $33.1 \%$ in rural Central India $33.1 \%{ }^{11}$ In a study conducted in Jodhpur, the incidence of TLBW was $22.46 \%$, which is very high compared to this study. ${ }^{5}$

Maternal age, height, weight, parity, history of abortion, or infertility history were not showing any statistically significant association with TLBW in this study. Only BMI distribution between the two groups was statistically significant. It was found that more underweight women belonged to the case group compared to the control group. Still, as a variable, the mother's weight or height did not show any statistically significant association with TLBW in this study. The majority of the mothers in the control group were overweight or obese. Other studies had shown a significant association of LBW with maternal weight and height. ${ }^{8,12,13}$ Ismail et al conducted a study in Kerala and found out that any height less than $155 \mathrm{~cm}$ for the pregnant women can be categorized as a high-risk pregnancy. ${ }^{8} \mathrm{~A}$ study done by Yadav et al in Nepal showed that age $<20$ years and the mother's height and weight were significantly associated with LBW. They had reported that women with pre-pregnancy weight $<50 \mathrm{~kg}$ were three times more likely to have an LBW baby when compared to women whose weight was $>50 \mathrm{~kg} .{ }^{14}$ Another study conducted in Nepal showed that women with a weight of $<45 \mathrm{~kg}$ had nearly 5 times more risk of having an LBW baby. ${ }^{15}$

This study showed no association between TLBW and age. A study conducted in Brazil showed a significant association of TLBW with mothers' age in the age group, 35 to 49 years. ${ }^{11}$ Some studies showed a significant association of LBW with the age of the mother. ${ }^{12,16,17} \mathrm{~A}$ study conducted by Deka et al showed a significant association between LBW and the mother's weight, but the association with height was not statistically significant. ${ }^{17}$ A case-control study done in Nepal showed that women with age below 20 years during pregnancy had an increased chance of delivering neonates with low birth weight.14 Similar results were demonstrated by some other studies. ${ }^{12,18}$ A multivariate analysis conducted by Dasgupta et al also showed a significant association between mother's age (below 20 years) and LBW. ${ }^{19}$ None of the mothers in this study were below 20 years of age.

Some studies had shown that younger nulliparous women were more likely to have low birth weight babies when compared with multiparous counterparts. A study conducted by Raman et al showed that $40.7 \%$ of the small for gestational age babies were born to primigravidas. ${ }^{20} \mathrm{In}$ contrary to this, the study conducted by Sarika et al showed that multigravida mothers had a high prevalence of having LBW babies compared to primi mothers. ${ }^{21}$ Yadav et al had reported in their study that primigravida women had 4.58 times more chance of giving birth to an LBW baby. ${ }^{14} \mathrm{~A}$ study done in Karnataka had shown that grand multi-para women had 3.6 times more chance of having LBW babies. ${ }^{22}$ But few other studies from India did not show any significant association between parity and LBW. ${ }^{13,23}$ Our analysis also did not show any association between parity and TLBW. Some studies had reported a significant association between TLBW and the female gender of the baby. ${ }^{21,24,25}$ But this study does not show any association between TLBW and the gender of the baby.

Considering the risk factors in this study, anemia, UTI, genital tract infection, gestational hypertension, gestational diabetes (GDM), and antepartum hemorrhage showed no significant association with TLBW. Approximately $30-70 \%$ of the women in India are anemic. Ismail et al. conducted a study in Kerala and found that $15 \%$ of the mothers were anemic before pregnancy. Their research showed a significant association of LBW with anemia, gestational hypertension, GDM, pre-pregnancy weight, and maternal height and showed no significant association with the mother's parity status. ${ }^{8}$ Women with lower weight before pregnancy may not be adequately nourished, resulting in LBW babies' birth. ${ }^{26}$ Women born with LBW have a high likelihood of delivering LBW babies in the future. 4 Most of the studies showed a significant association of maternal anemia with LBW. ${ }^{4,5,12,16,21}$ But in this study, $93.7 \%$ of the population in the case group and $97.1 \%$ in the control group were not anemic. Only a few mothers were found to have anemia, but this was not statistically significant. This may be because Kerala's health indices are high above the national average, and the study was conducted in an urban population. ${ }^{9}$

The study showed a significant association between LBW and hypothyroidism in mothers $(p=0.006)$. This may be because of the high prevalence of hypothyroidism seen among pregnant women in Kerala. An institutional study conducted by Justin et al. among pregnant women in Kerala showed that $10.54 \%$ of the pregnant women were hypothyroid, and $17.72 \%$ of the hypothyroid mothers gave birth to LBW babies. ${ }^{27}$

In Kerala, deliveries occur primarily in hospitals, and most women visit the hospital regularly for antenatal checkups. Women delivering in private medical setup had better outcomes than those delivering in government setup. ${ }^{8}$ Good antenatal care was found to reduce the risk of LBW babies. ${ }^{4}$ This helps to increase the awareness among pregnant women and identify high-risk pregnancies at the correct time so that appropriate interventions can be made to reduce the number of LBW babies. This may be the reason for the low incidence of TLBW which was found in this institutional study in South Kerala, whereas other studies had shown the prevalence of LBW which included both term and pre-term.

\section{Limitations}

This is an institutional study conducted in a tertiary care center. A multicenter study will be a better design to further explore the relationship between LBW and risk 
factors that may lead to a comparable incidence rate reported early in Asian population. As the study was based on medical records, factors like socioeconomic status and education level of pregnant women, and other environmental risk factors could not be assessed.

\section{CONCLUSION}

The incidence of TLBW in this institutional study conducted in urban population was $4.68 \%$, which is very low compared to other studies. Considering the common risk factors like anemia, UTI, genital tract infection, gestational hypertension, gestational diabetes, hypothyroidism, and antepartum hemorrhage, only hypothyroidism was significantly associated with TLBW.

Funding: No funding sources

Conflict of interest: None declared

Ethical approval: The study was approved by the Institutional Ethics Committee

\section{REFERENCES}

1. Ganchimeg T, Ota E, Morisaki N, Laopaiboon M, Lumbiganon $\mathrm{P}$, Zhang $\mathrm{J}$, et al. Pregnancy and childbirth outcomes among adolescent mothers: a World Health Organization multicountry study. BJOG. 2014;121:40-8.

2. UNICEF. Low Birth Weight: Country, Regional, and Global Estimates. New York, NY, USA. 2004.

3. Singh M. Care of the new born revised. 2017. Available at: https://books.google.com/books?hl=en $\& 1 \mathrm{r}=\& \mathrm{id}=\mathrm{Wv} 9 \mathrm{qDwAAQBAJ} \& \mathrm{oi}=\mathrm{fnd} \& \mathrm{pg}=\mathrm{PP} 14 \&$ ot $\mathrm{s}=5 \mathrm{IdXb3UzB} 8 \&$ sig=dzkN_2evEG_V3FDAQp8q8Z Tv5qI. Accessed on: 21 March 2021.

4. Khan A, Nasrullah FD, Jaleel R. Frequency and risk factors of low birth weight in term pregnancy. Pakistan J Med Sci. 1969;32(1):138-42.

5. Bhimwal RK, Makwana M, Chouhan HK, Gupta M, Lal K, Jora R. A study of various determinates and incidence of low birth weight babies born in Umaid hospital, Jodhpur (Western Rajasthan). Int J Contemp Pediatr. 2017;4(4):1302.

6. India MoH and FWG of Health and Family Welfare statistics in India, 2019-20. Ministry of Health and Family Welfare, Government of India. Available at: http://www.searo.who.int/india/tobacco/ smokeless_ tobacco_and_public_health_in_india.pdf?ua=1\%0Ah ttp://www.searo.who.int/india/tobacco/smokeless_to bacco_and_public_health_in_india.pdf?ua=1\%0Ahtt ps://nrhm-mis.nic.in/UI/FamilyWelfare 2013/Compl ete/BOOK.pdf. Accessed on: 22 March 2021.

7. International Institute for Population Sciences. National Family Health Survey-4 (NFHS-4) State Fact Sheet, Odisha. Ministry of Health and Family Welfare. Government of India. 2016;90.

8. Ismail IM, Venugopalan PP. Case-control study on risk factors of low birth weight in a tertiary care hospital, Kerala. Ann Comm Health. 2016;4(3):5-12.
9. Thankappan RK, Valiathan MS. Health at low costThe Kerala model. Lancet. 1998;351(351):1274-5.

10. U.S. Infant Mortality Rate 1950-2021. MacroTrends. Available at: https://www.macrotrends.net/countries /USA/united-states/infant-mortality-rate. Accessed on 22 March 2021.

11. Falcão IR, Ribeiro-Silva RDC, de Almeida MF, Fiaccone RL, Dos S Rocha A, Ortelan N, et al. Factors associated with low birth weight at term: a populationbased linkage study of the 100 million Brazilian cohort. BMC Pregnancy Childbirth. 2020;20(1):536.

12. Pal A, Manna S, Das B, Dhara PC. The risk of low birth weight and associated factors in West Bengal, India: a community based cross-sectional study. Egypt Pediatr Assoc Gaz. 2020;68(1):27.

13. Mumbare SS, Maindarkar G, Darade R, Yengl S, Tolani MK, Patole K. Maternal risk factors associated with term low birth weight neonates: A matched-pair case control study. Indian Pediatr. 2012;49(1):25-8.

14. Yadav DK, Shukla GS, Gupta N, Shrestha N, Singh A, Kaphle HP. Maternal and Obstetric Factors Associated with Low Birth Weight. J Nepal Health Res Counc. 2020;17(4):443-50.

15. Bhaskar RK, Deo KK, Neupane U, Chaudhary Bhaskar S, Yadav BK, Pokharel HP, et al. A Case Control Study on Risk Factors Associated with Low Birth Weight Babies in Eastern Nepal. Int J Pediatr. 2015;2015:1-7.

16. Anand P, Gupta R, Sudan JK. Prevalence of Low Birth Weight and Associated Maternal Risk Factors among the Term Neonates during Normal Deliveries in Jammu, J\&K. Int J Health Sci Res. 2019;9(8):376.

17. Deka A, Saharia NP, Bihani A. A study on maternal factors associated with low birth weight newborns. Index Copernicus Int. 2018;7(2):82-8.

18. Negi KS, Kandpal SD, Kukreti M. Epidemiological factors affecting low birth weight. JK Sci. 2006;8(1):31-4.

19. Dasgupta A, Basu R. Determinants of low birth weight in a Block of Hooghly, West Bengal: A multivariate analysis. Int $\mathbf{J}$ Biol Med Res. 2011;2(4):838-42.

20. Raman Tr, Devgan A, Sood S, Gupta A, Ravichander B. Low Birth Weight Babies: Incidence And Risk Factors. Med J Armed Forces India. 1998;54(3):191-5.

21. Sarika DM, Vishwakarma DR, Rao DR, Sarika DM, Vishwakarma DR, Rao DR. Study of low birth weight babies and their association with maternal risk factors. Pediatr Rev Int J Pediatr Res. 2020;7(7):379-87.

22. Metgud CS, Naik VA, Mallapur MD. Factors Affecting Birth Weight of a Newborn - A Community Based Study in Rural Karnataka, India. Szecsi PB, editor. PLoS One. 2012;7(7):e40040.

23. Kader M, Perera NP. Socio-economic and nutritional determinants of low birth weight in India. $\mathrm{N}$ Am J Med Sci. 2014;6(7):302.

24. Kumar V, Deshmukh PR, Taywade M, Gupta SS. Magnitude and correlates of low birth weight at term 
in rural Wardha, Central India. Online J Heal Allied Sci. 2016;15(1):1-5.

25. Agorinya IA, Kanmiki EW, Nonterah EA, Tediosi F, Akazili J, Welaga $P$, et al. Socio-demographic determinants of low birth weight: Evidence from the Kassena-Nankana districts of the Upper East Region of Ghana. PLoS One. 2018;13(11).

26. Ramakrishnan U. Nutrition and low birth weight: from research to practice. Am $\mathrm{J}$ Clin Nutr. 2004;79(1):17-21.
27. Justin SA, Johnson MS. A prospective study on evaluation of maternal and foetal outcomes of hypothyroidism with levothyroxine and prevalence of hypothyroidism in pregnancy in a tertiary care teaching hospital in Kerala. Int $\mathbf{J}$ Basic Clin Pharmacol. 2020;9(3):392.

Cite this article as: Jacob S, Jacob AT. Incidence and risk factors for term low birth weight babies in a tertiary care hospital in Kerala. Int J Reprod Contracept Obstet Gynecol 2021;10:1795-801. 